\title{
Study of corrosion by Dynamic Gravimetric Analysis (DGA) methodology. Influence of chloride content in solar salt
}

\author{
Cristina Prieto ${ }^{2}$, Juan Gallardo-González ${ }^{1}$, Francisco Javier Ruiz-Cabañas ${ }^{2}$, Camila \\ Barreneche $^{1,}$, Mònica Martínez ${ }^{1}$, Mercè Segarra ${ }^{1}$, A. Inés Fernández ${ }^{1}$ \\ ${ }^{1}$ Department of Materials Science \& Physical Chemistry, Universitat de Barcelona, Martí i \\ Franqués 1, Barcelona 08028, Spain. Email: ana_inesfernandez@ub.edu \\ ${ }^{2}$ Abengoa Research, C/ Energía Solar n ${ }^{\circ}$ 1, Palmas Altas,41014-Sevilla
}

\begin{abstract}
When a system for thermal energy storage (TES) is designed, many factors must be considered: storage time, dimensions, material to store heat, etc. Usually, molten salts are selected as TES materials because of their great thermal properties at high temperatures. When the whole TES system is going to be built, the material to be used for containing the thermal storage material becomes an important issue. It must have proper mechanical properties, withstand high temperatures and, above all, resist corrosion due to storage material, being in most of the cases, highly corrosive molten salt mixtures. To determine the corrosion on a metal plate, ASTM Standard-G1-03 procedure is usually applied, in which the corroded metal sample is submitted to several cycles including: attack by a chemical solution, washing, cleaning, drying, and weighing. In order to minimize the handling of the sample, a new methodology (Dynamic Gravimetric Analysis, DGA) has been developed and used to determine the corrosion produced in carbon steel A516Gr70 samples induced by different salt mixtures commonly used as molten salts containing different amounts of chloride, at working temperatures conditions. The results show that the higher is the content of chloride in molten salts the greater is the steel loss produced by corrosion and makes the corrosive kinetics to be highly increased when it is overtaken.
\end{abstract}

Keywords: Corrosion, dynamic gravimetric analysis (DGA), ASTM G1-03, thermal energy storage (TES), molten salts, sensible heat 


\section{Introduction}

Nowadays, worldwide energetic supply is being one of the most important targets as the global population growth and industrial development make the energy consumption to be increased [1][2]. This results in the massive exploitation of energy resources, primarily fossil fuels. As a consequence of its demands, the emissions of carbon dioxide have increased, as well as their prices [3][4]. This fact, in addition to pollution issue from fossil fuels, has become a matter of concern for most developed countries in which renewable alternative energies are being studied to support energy peaks [5][6][7].

In order to minimize costs and environmental impact, fossil fuels are being replaced for other renewable energies, such as thermosolar energy, wind, photovoltaic, among many others, that have less costs and no environmental pollution. There have been a rising number of investigations regarding the deployment of renewable energy in order to advance to a new energy model, ensuring less environmental damage and less economical costs [1]. As it has almost no environmental concerns, concentrating solar power (CSP) generation is becoming a very attractive renewable energy system among all the renewable options, as well as it has a better potential for dispatchability [8]. Although the CSP technologies date back to 1970s, most of the commercial plants have been developed in the last decade. To date, Spain ( 60\%) and the United States $(\sim 40 \%)$ are the two largest markets for the CSP technologies, and the world's largest CSP plant was commissioned in the USA in 2014 (Ivanpah Dry Lake, CA). Furthermore, the International Energy Agency (IEA) has set an electricity generation target of 630 GWe for CSP technology by 2050 [9].

Basically, solar thermal power plants produce electricity using solar radiation as energy input. This concentrated power is used to warm up thermal energy storage (TES) material which will store it as heat. Molten salts exhibit many desirable heat transfer properties at high temperatures. They have high density, high heat capacity, high thermal stability, and very low vapour pressures even at elevated temperatures what make them to be thoroughly used as TES material. There are several commercial salt formulations available in the market based commonly in nitrates, nitrites, carbonates, chlorides, fluorides and mixtures of them depending on the desired properties close to the working temperature range [8]. Thereby, the state-of-the-art TES materials for CSP mainly consist of alkali metal nitrate salt mixtures and to some extent alkali metal nitrite and alkaline earth metal nitrate salts [9]. Nevertheless, this kind of inorganic salts present a major drawback: they are highly corrosives. The molten nitrate salts in combination with the metallic parts of solar power plants constitute a corrosive system with the molten salt acting as an electrolyte comparable to an aqueous electrolyte. Whereas the corrosion 
mechanisms of metals in numerous aqueous electrolytes are well established and well understood, there still exists a lack of knowledge concerning the corrosion mechanisms of metals under the working conditions for molten nitrate salts in CSP plants. Therefore, potential vessel materials (usually stainless and carbon steel) have to be experimentally tested in order to establish their corrosion behaviour before being suitable for a TES system [10][11]. The main expenses of these systems depend on both the employed structural material, such as steel, and the purity of the constituents used to prepare the molten salts batch, as large quantities of them are needed [12][13]. Chloride, as $\mathrm{NaCl}$ and/or $\mathrm{KClO}_{4}$, is the main impurity, which can be present in concentrations up to approximately $1 \mathrm{wt} \%$ in commercial grades of the constituent salts [14], associated to pipe and tank corrosion. Previous works have reported details on the influence of impurities on the corrosion kinetics and resistance, and the oxide growth mechanism of carbon steels in molten nitrate salts [15]. However, there is little specific information about the influence of impurities on the mechanical integrity of oxide layers in carbon steels, which can be associated to the corrosion kinetics and resistance. Ideally, an oxide layer should be dense and have a good adhesion on the surface, as long as possible, without forming cracks or pores, to protect the corrosion of carbon steel.

The aim of this paper is to study the corrosion produced on carbon steel $\mathrm{A} 516 \mathrm{Gr} 70$ at $400^{\circ} \mathrm{C}$ in $\mathrm{N}_{2}$ atmosphere and different exposure times, by three different mixtures of well-known molten salts currently studied and used in TES. The studied salts have different chloride contents, to evaluate its influence on the corrosion rate. To reach the main goal of this paper, a new methodology to measure the corrosion has been developed by the authors, based on ASTM Standard-G1-03 [16].

\section{Materials and Methodology}

The material tested in this study was carbon steel A516Gr70, whose composition, analysed by optical emission spectrometry (OES) using the spectrometer Thermo Scientific ARL 3460 device, is shown in Table 1. This composition differs from the one specified in the ASTM standard, that stablish a maximum value for Si content $(0.40 \%)$, and should be corroborated with further analysis if required. The rest of elements ( $\mathrm{Al}, \mathrm{Cr}, \mathrm{Cu}, \mathrm{Ni}, \mathrm{Mo}, \mathrm{Nb}, \mathrm{Ti}$ and $\mathrm{V}$ ) analysed by OES are not defined in the ASTM standard. Several pieces measuring $38 \mathrm{~mm} \times 10$ $\mathrm{mm}$ were cut from a sheet with a thickness of $3.5 \mathrm{~mm}$. A hole with $2 \mathrm{~mm}$ diameter was made at one end of each piece for further being hanged in the gravimetric device. The preparation of the metal samples was the following: they were firstly ground using increasingly finest grades of abrasive paper to remove any metal oxide layers adhered on the surface, further polished using 
diamond suspensions ( 6 and $1 \mu \mathrm{m}$ ), and followed by cleaning in an acetone sonicator. The plates were then weighed and dimensions were recorded.

Table 1. Composition of carbon steel A516Gr70.

\begin{tabular}{cc}
\hline Element & Weight percentage (\%) \\
\hline $\mathrm{C}$ & 0.10 \\
$\mathrm{Si}$ & 0.60 \\
$\mathrm{Mn}$ & $1-1.7$ \\
$\mathrm{P}$ & 0.03 \\
$\mathrm{~S}$ & 0.03 \\
$\mathrm{Al}$ & 0.02 \\
$\mathrm{Cr}$ & 0.30 \\
$\mathrm{Cu}$ & 0.30 \\
$\mathrm{Ni}$ & 0.30 \\
$\mathrm{Mo}$ & 0.08 \\
$\mathrm{Nb}$ & 0.01 \\
$\mathrm{Ti}$ & 0.03 \\
$\mathrm{~V}$ & 0.02 \\
\hline
\end{tabular}

To simulate the corrosion under operating conditions, each steel sample (with three replicates) was immersed in a reactor filled with a sample of nitrate salts usually used for CSP plants. Table 2 shows the salts compositions. Solar salt is the formulation reported in the literature with a composition $60: 40 \mathrm{NaNO}_{3}$ and $\mathrm{KNO}_{3}$ by weight close to the eutectic composition. Both salts were supplied by SQM: $\mathrm{NaNO}_{3} \mathrm{SSI}$ industrial grade and $\mathrm{KNO}_{3} \mathrm{NPC}-\mathrm{T}$ technical grade having as main impurity chloride and in less extent nitrites and sulphates. The other two samples have different additions of $\mathrm{NaCl}$ resulting in different chloride contents.

Table 2. Composition of the molten salts mixtures used for the corrosion tests.

\begin{tabular}{lccc}
\hline \multicolumn{1}{c}{$(\mathbf{w t} \%)$} & $\mathbf{N a N O}_{\mathbf{3}}$ & $\mathbf{K N O}_{\mathbf{3}}$ & ${\text { chloride } \mathbf{C l}^{-}}^{-}$ \\
\hline Solar salt [17][18] & 60.0 & 39.9 & 0.2 \\
SsChloride 0.7 & 59.3 & 39.5 & 0.7 \\
SsChloride 1.8 & 58.3 & 38.8 & 1.8 \\
\hline
\end{tabular}


The thermal-corrosive treatment was performed in an experimental set up shown in Figure 1. This set-up was developed by the authors and consists of six tubular reactors made of stainless steel AISI-304, whose temperature is controlled by 6 type-K thermocouples (one for each reactor). The atmosphere inside each tubular reactor is also controlled in order to manage independent but equal atmospheres of $\mathrm{N}_{2}$. Finally, the tubular reactors are located inside a furnace with its temperature controlled up to $600{ }^{\circ} \mathrm{C}$. Each steel sample is introduced into an alumina crucible fulfilled by the selected molten salt, which is placed within each reactor, to prevent its corrosion. The temperature inside each reactor has been established at $400^{\circ} \mathrm{C}$ while having $100 \%$ wt. of $\mathrm{N}_{2}$ atmosphere inside them. Each sample has been removed from the corrosive environment after different exposure times.
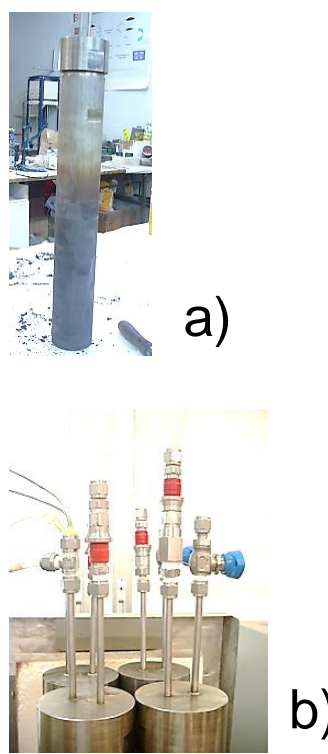

)
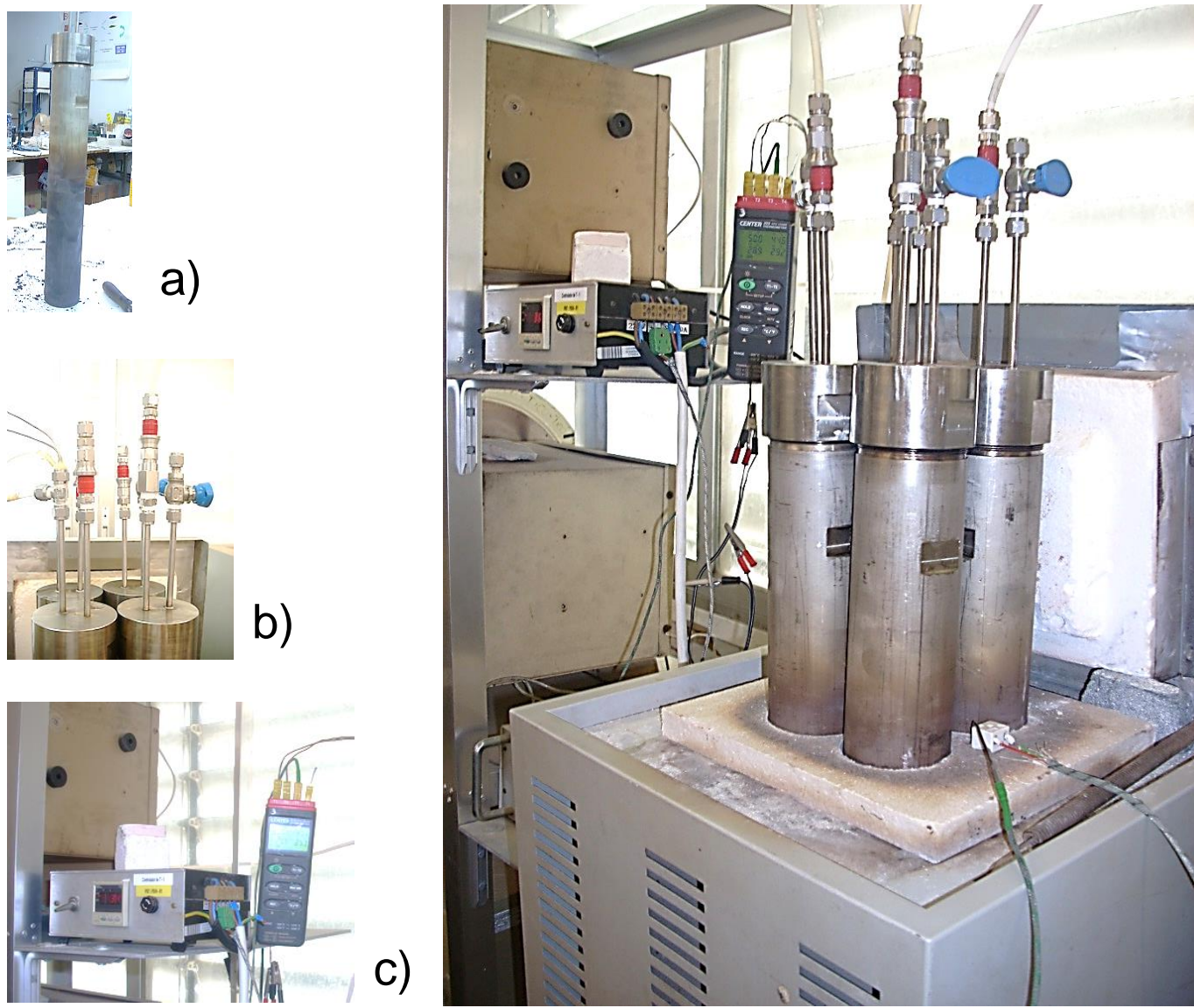

d)

Figure 1. Thermal-corrosive treatment: parts of the experimental set-up a) tubular reactor, b) atmosphere controller, c) temperature controller and data-logger, d) general view of the experimental set-up.

After the corrosion test with the different compositions of molten salts, the amount of corrosion products formed on the surface of each metal sample was determined by using the new 
methodology developed at University of Barcelona named dynamic gravimetric analysis (DGA). Commonly, the methodology to evaluate the corrosion proposed by the ASTM standard (G1-03) [16] has been widely used in many fields. The procedure involves having the corroded metal immersed in Clark solution that reacts with the scale layer [18]. The procedure involves an intensive sample manipulation because of the manual brushing performed by the technician, and thus the results are dependent on the ability the technician has to perform this operation several times. Recently, researchers from the University of Barcelona have developed a new methodology, based on the ASTM Standard-G1-03, which avoids the sample manipulation. The variation from the ASTM Standard, where several solutions are recommended to remove the corrosion products formed on different metals, is to handle the sample as less as possible. In order to achieve this goal, the sample in contact with the cleaning solution defined for each metal in the ASTM mentioned before (in this case, for steel is defined the Clarke solution that consists of 1 liter 1.49 s.p. gr $\mathrm{HCl}, 25 \mathrm{~g} \mathrm{Sb}_{2} \mathrm{O}_{3}$, and $50 \mathrm{~g} \mathrm{SnCl}_{2}$ ) is hung from an analytical balance as shown in Figure 2. Thereby, the sample remains hanging from the balance till the cleaning solution starts to attack the metal (in this case carbon steel A516Gr70) after removing all the metal oxide. This point is detected by a slope change in the mass loss vs. time registered. Therefore, the corroded layer is eroded by the cleaning solution avoiding the handling. Hence, the human brushing factor is removed and this methodology provides more accurate corrosion rate results than the ASTM standard.

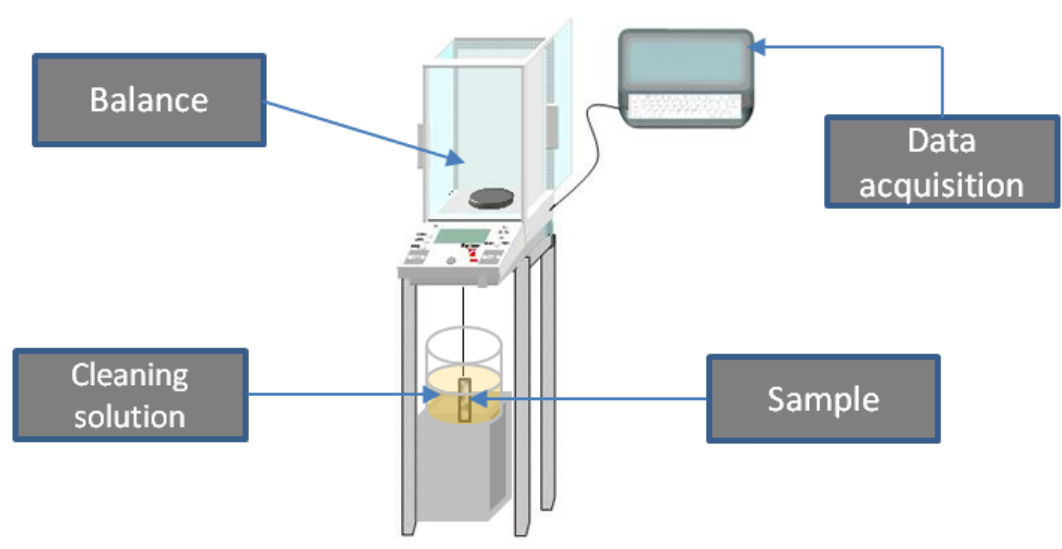

Figure 2. Dynamic Gravimetric Analysis (DGA).

Following the DGA procedure, the samples were hung on a platinum wire and fully submerged into a glass beaker containing the chemical cleaning solution for $2 \mathrm{~h}$, thus allowing the rust to be cleaned during this time. This cleaning time was optimized based on previous tests. Since an analytical balance (Ohaus Explorer with an accuracy of $\pm 0.1 \mathrm{mg}$ ) was connected to a computer (software RealTerm: Serial Capture Program 2.0.0.43) the weight can be recorded at a speed around a reading per second, and plotted against time to obtain a curve from which the amount of oxide can be calculated. The dissolution rate of the oxide is different from the dissolution rate 
of the metal base. Therefore, a change in the slope of the curve is expected that indicates the point at which all the oxide has been removed.

During thermal treatment of the samples some of the formed scales can be delaminated and lost during sample removing from the crucibles. So the weight of the sample after thermal treatment $\left(w_{0}\right)$ is not representative of the amount of oxidized metal. Another question to take into account is the buoyancy, as the weight inside the solution is not the same as in air, as well as the weight loss. But from the curve we can determine the point at which all the oxide is removed $\left(w_{o x}{ }^{\text {Clarke }}\right.$ ) and metal base starts to be corroded. By comparing the final and the initial weights, inside and outside the dissolution, formed rust can be calculated and expressed in microns of oxide layer thickness. Average descaled weight loss of three samples was used to determine the corrosion rate. The steel loss during thermal treatment per unit surface area (in $\mu \mathrm{m} / \mathrm{cm}^{2}$ ) can be calculated by next equation:

$$
x_{\text {steel }}=\frac{w_{i}^{\text {air }}-\left[w_{f}^{\text {air }}-\left(w_{f}^{\text {Clarke }}-w_{o x}^{\text {Clarke }}\right) B\right]}{S \rho}
$$

where $w_{i}^{a i r}$ is the initial weight of the sample, $w_{f}^{\text {air }}$ is the weight after the DGA test, $w_{f}^{\text {Clarke }}$ is the final weight of the sample inside the Clarke cleaning solution, $w_{o x}$ Clarke is the weight of the sample inside the Clarke solution when all the oxide layer has been removed, $B$ is the solvent buoyancy, $S$ is the surface area (in $\mu \mathrm{m}^{2}$ ), and $\rho$ the oxide layer density (in $\mathrm{g} / \mathrm{cm}^{3}$ ). Experimented buoyancy is calculated as the relation between the weight loss of the sample outside ( $\left.\Delta w^{\text {air }}\right)$ and inside $\left(\Delta w^{\text {Clarke }}\right)$ the dissolution, as expressed in Eq. 2.

$B=\frac{\Delta w^{\text {air }}}{\Delta w^{\text {Clarke }}}=\frac{w_{f}^{\text {air }}-w_{o}^{\text {air }}}{w_{f}^{\text {clarke }}-w_{o}^{\text {Clarke }}}$

where $w_{o}{ }^{a i r}$ and $w_{o}$ Clarke are the weights of the sample after removing it from the thermal treatment and before starting the DGA test, before and after immersing it into the Clarke solution, respectively.

The scales and corrosion products were examined for the Solar salt and SsChloride 0.7samples, in polished cross-sections by Scanning Electron Microscopy (SEM), and Energy Dispersive Xray Microanalysis (EDX). Moreover, X-ray diffraction (XRD) analysis was performed on oxide surface to determine the corrosion products. 


\section{Results and discussion}

\subsection{Compositional and morphological analysis}

XRD patterns results of the corroded samples at the different exposure times are summarized in

Table 3. The analyses showed that the main oxides formed, in both molten nitrate salts containing 0.2 and $0.7 \mathrm{wt} \%$ chloride, were magnetite, $\mathrm{Fe}_{3} \mathrm{O}_{4}$, (76-88\%) and hematite, $\mathrm{Fe}_{2} \mathrm{O}_{3}$, (12-24\%). The hematite presence at a test time of $168 \mathrm{~h}$ (7 days), in both chloride contents, was relatively higher than that above exposure times. However, this result could be due to the interference with substrate in XRD when the oxide layer has a few micrometers. In addition, the content of chloride did not significantly affect the formation of more hematite with respect to the magnetite phase at any exposure time. Figure 3 shows the XRD patterns and the corresponding peak identification chart of the surface scale formed on two samples: the Solar salt containing $0.2 \mathrm{w} \%$ chloride (SsChloride 0.2) and the sample SsChloride 0.7 after $2160 \mathrm{~h}$ (90 days). The main oxide detected was magnetite $\left(\mathrm{Fe}_{3} \mathrm{O}_{4}\right)$, corresponding to the green lines, and hematite $\left(\mathrm{Fe}_{2} \mathrm{O}_{3}\right)$ peaks (blue lines) were also observed. Moreover, XRD also detected the steel, indicated by the black lines, due to the steel substrate beneath the relatively thin oxide scale. These results are in agreement with previous studies of corrosion tests reported by Bradshaw et al. [19].

Table 3. Amounts of corrosion products, analyzed by XRD analysis, after different test times.

\begin{tabular}{cccc}
\cline { 2 - 4 } & $\begin{array}{c}\text { Testing } \\
\text { time } \\
\text { (hours) }\end{array}$ & \multicolumn{2}{c}{ Phase (wt\%) } \\
$\mathbf{F e}_{3} \mathbf{O}_{4}$ & $\mathbf{F e}_{\mathbf{2}} \mathbf{O}_{3}$ \\
\hline Solar salt & $\mathbf{1 6 8}$ & 78 & 22 \\
& $\mathbf{3 3 6}$ & 83 & 17 \\
& $\mathbf{6 9 5}$ & 86 & 14 \\
& $\mathbf{1 5 0 4}$ & 84 & 16 \\
& $\mathbf{2 1 6 5}$ & 82 & 20 \\
\hline \multirow{5}{*}{ SsChloride0.7 } & $\mathbf{1 6 8}$ & 76 & 24 \\
& $\mathbf{3 3 6}$ & 80 & 20 \\
& $\mathbf{6 9 5}$ & 81 & 19 \\
& $\mathbf{1 4 2 1}$ & 78 & 21 \\
& $\mathbf{2 1 6 0}$ & 79 & 22 \\
\hline
\end{tabular}




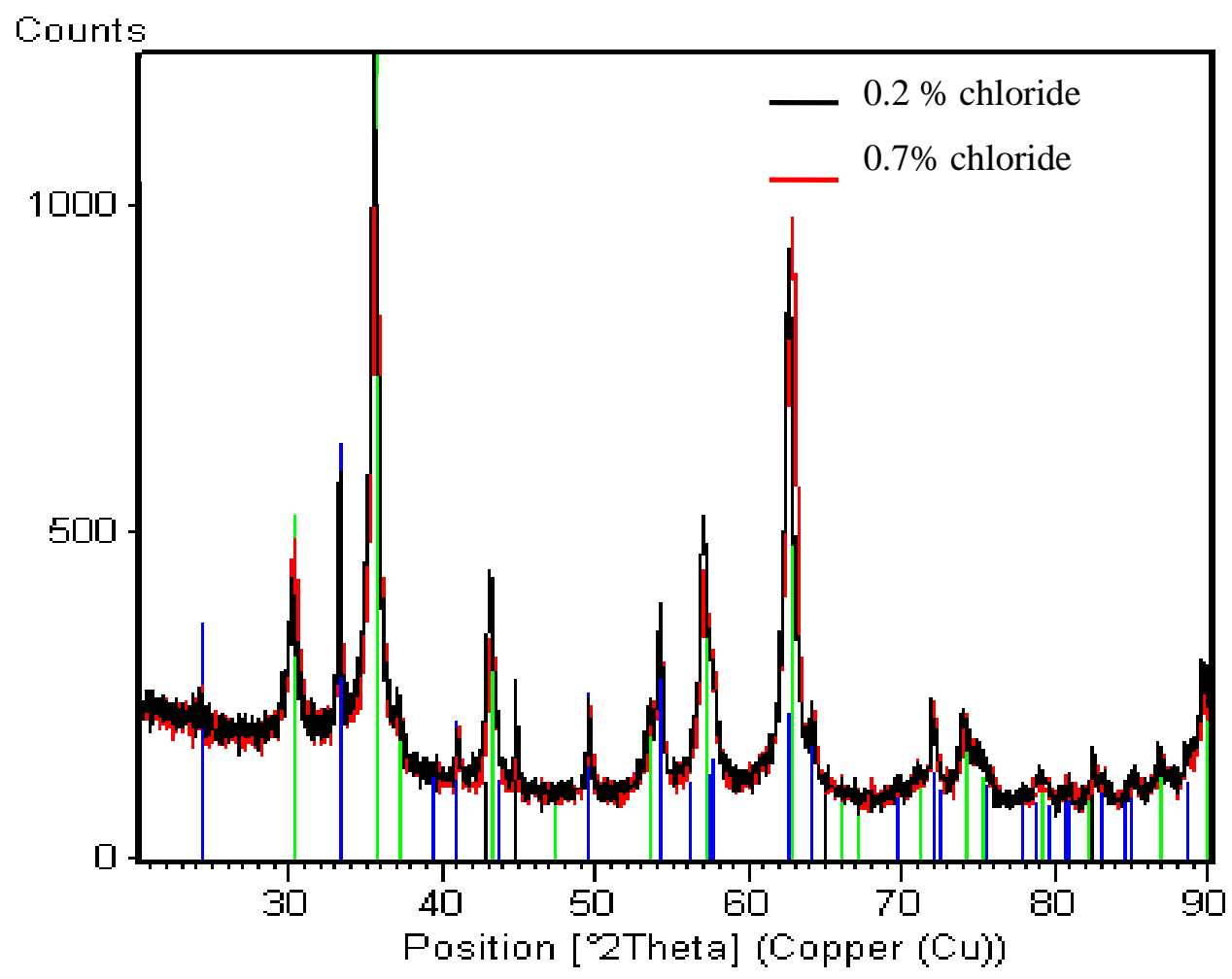

Figure 3. XRD patterns and corresponding peak identification chart of the surface scale formed on the samples Solar salt and SsChloride 0.7 after 90 days. Magnetite peaks correspond to the green lines, hematite to the blue lines, and steel to the black lines.

Microstructures of oxides for both molten salt compositions (Solar salt and Chloride 0.7) at different exposure times are observed in Figure 4. The scale formed after low-test times (a), using solar salt compositions, appears to be compact and well adhered to the metal surface. In contrast, porosity, internal cracking, and delamination are more visible in the oxide layer when increasing exposure time (c and d). In addition, the oxide layers formed in the SsChloride 0.7 samples (e and f), were much thicker and presented higher porosity, including large voids. Therefore, it appears that the additional chloride contributes to increase the thickness of oxide layer, and to form more porosity and microcracks, as well as producing layer-substrate delamination, thus reducing the integrity of oxide layer. 


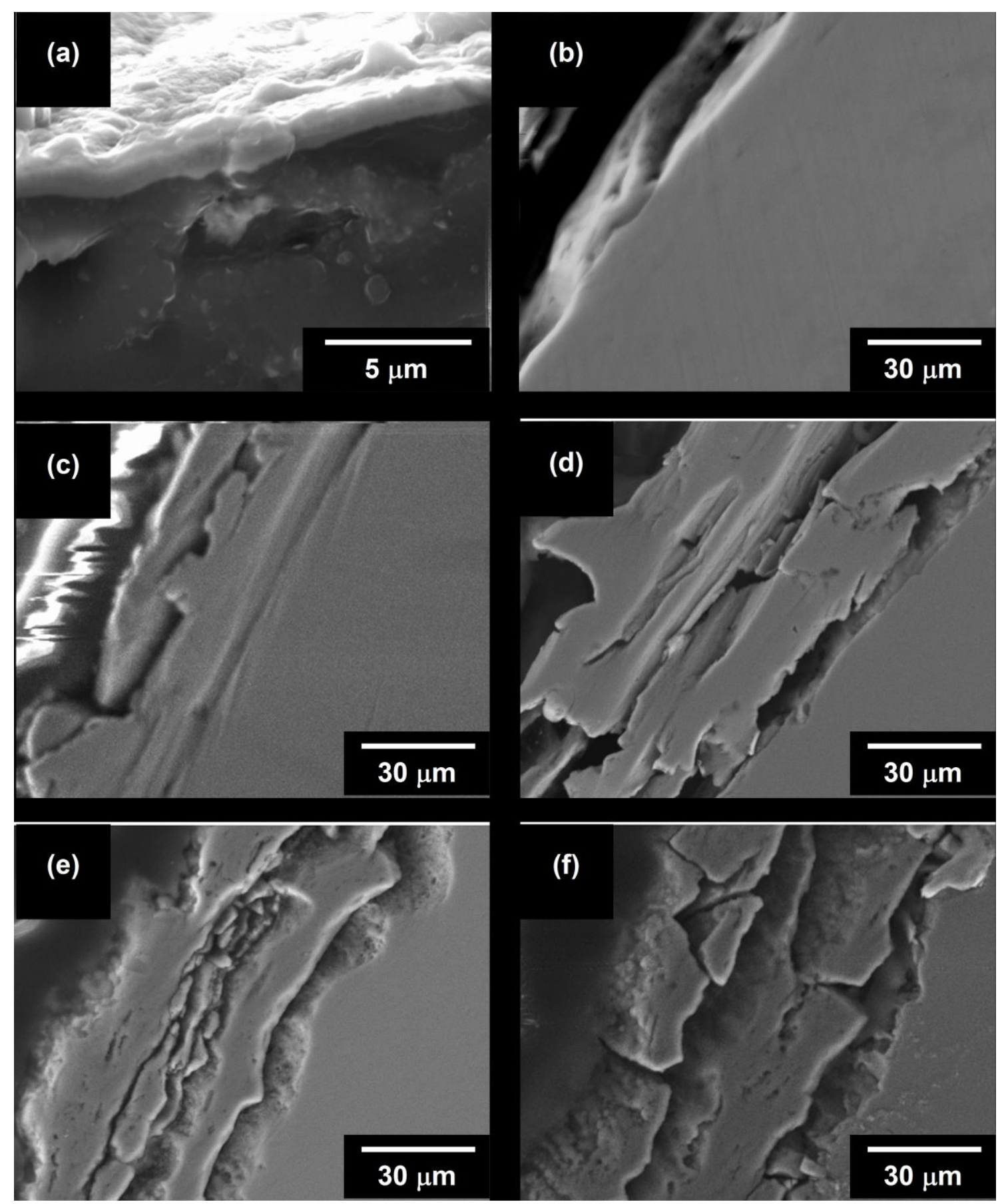

Figure 4. SEM micrographs of oxide layer after different exposure times immersed in Solar salt sample a) 168 h, b) 695 h, c) 1504 h, d) 2165 h, and immersed in SsChloride 0.7 e) 1421 h, and f) 2160 h.

\subsection{Corrosion rates}

To determine the amount of oxide layer removed by the cleaning solution with accuracy, the mass of the sample is plotted versus time during the DGA. As the cleaning has been kept for 2 hours for all the samples, once the scale is removed, the steel will begin to be oxidized by the 
cleaning solution. These two processes, dissolution of scale and corrosion of steel by the cleaning solution, will take place at different rates as they correspond to two different chemical reactions. Thus, the plot must show a change in the slope due to the change of controlling mechanism, that can be related to the moment at which the rust has completely been removed and the metal specimen starts to be attacked. The amount of oxide formed during corrosion in molten salts is expected to be different for each sample, so the change in the slope should be found at different times (and therefore at different mass losses), depending on the amount of scale formed during the immersion in molten salts.

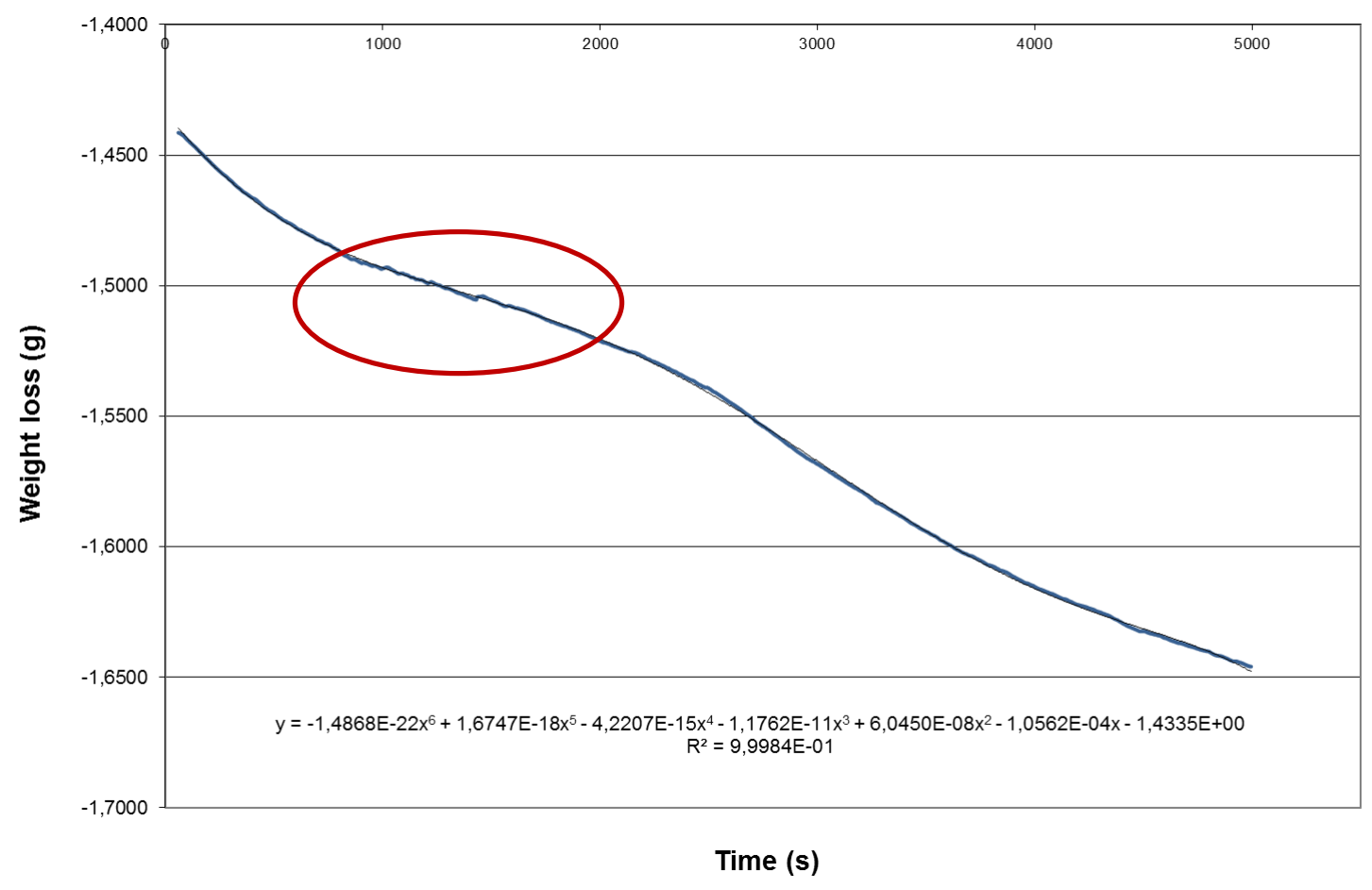

Figure 5. Mass loss of a corroded sample during DGA cleaning procedure and adjusted polynomic curve.

Figure 5 shows an example of the mass dissolved by the cleaning solution with time for one of the samples cleaned with Clarke solution by DGA methodology. The first points of the recorded data are not included in the plot, and were rejected as the buoyancy has a great effect on the weight when immersing the sample into the dissolution after tare the balance. The point on the graph in which the slope changes (red circle) will correspond to the final value where all corrosion products have been removed $\left(w_{o x}^{\text {Clarke }}\right)$. In order to determine more accurately this point, experimental data have been adjusted by a polynomic equation $\mathrm{f}(\mathrm{x})$, and the first and second derivatives calculated $\left(\mathrm{f}^{\prime}(\mathrm{x})\right.$ and $\mathrm{f}^{\prime}(\mathrm{x})$, respectively). The point on the graph in which $\mathrm{f}^{\prime}(\mathrm{x})=0$ and $\mathrm{f}^{\prime}(\mathrm{x})=0$ will correspond to the point in which the slope changes, and so $w_{o x}$ Clarke 
can be obtained from that value. Once initial and final weights, surface area, volume and density are known, it is possible to calculate the scale thickness or alternatively the steel loss (in $\mu \mathrm{m}$ of thickness or $\mathrm{mg} / \mathrm{cm}^{2}$ ) for the different exposure times. Samples were treated by three replicates, and the averages of the steel loss per unit surface used to calculate the corrosion kinetics. Results are obtained from weight loss of samples calculated assuming uniform surface recession, which is an accepted assumption for carbon steel corrosion under these test conditions. Table 4 summarizes the results obtained.

Table 4. Oxide layer thickness and steel weight loss per unit surface for the samples studied.

\begin{tabular}{lcrrrrrr}
\hline Salt mixture & $\begin{array}{c}\text { Testing time } \\
(\text { hours })\end{array}$ & \multicolumn{2}{c}{$\begin{array}{c}\text { Metal loss } \\
\left(\mathbf{m g} / \mathbf{c m}^{2}\right)\end{array}$} & \multicolumn{3}{c}{$\begin{array}{c}\text { Annual loss rate } \\
(\boldsymbol{\mu m} / \text { year })\end{array}$} \\
\hline \multirow{5}{*}{ Solar salt } & 24 & 1.2 & \pm & 0.2 & 644.2 & \pm & 69.5 \\
& 168 & 2.6 & \pm & 0.1 & 170.4 & \pm & 4.3 \\
& 336 & 2.8 & \pm & 0.5 & 92.6 & \pm & 16.8 \\
& 695 & 5.3 & \pm & 0.7 & 84.3 & \pm & 11.2 \\
& 1504 & 11.2 & \pm & 1.4 & 83.2 & \pm & 10.7 \\
& 2165 & 9.2 & \pm & 0.7 & 47.4 & \pm & 3.4 \\
\hline \multirow{5}{*}{ SsChloride 0.7} & 24 & 2.5 & \pm & 0.2 & 1149.7 & \pm & 92.0 \\
& 168 & 3.9 & \pm & 0.1 & 261.7 & \pm & 7.4 \\
& 336 & 2.6 & \pm & 0.1 & 87.1 & \pm & 2.6 \\
& 695 & 8.2 & \pm & 3.8 & 73.3 & \pm & 22.0 \\
& 1421 & 74.8 & \pm & 2.6 & 587.8 & \pm & 20.4 \\
SsChloride 1.8 & 2160 & 76.2 & \pm & 10.9 & 392.7 & \pm & 56.1 \\
\hline & 24 & 7.4 & \pm & 0.5 & 3461.7 & \pm & 222.5 \\
& 144 & 4.9 & \pm & 0.9 & 451.5 & \pm & 45.6 \\
& 744 & 140.6 & \pm & 0.4 & 2109.4 & \pm & 6.3 \\
& 1504 & 133.1 & \pm & 2.5 & 987.3 & \pm & 18.6 \\
\hline
\end{tabular}

The samples exposed to the SsChloride 1.8 salt mixture exhibited larger weight losses than the ones immersed in the solar salt without additional chloride. The results of corrosion kinetics given as steel loss per unit surface vs time of exposure can be compared in Figure 6 . 


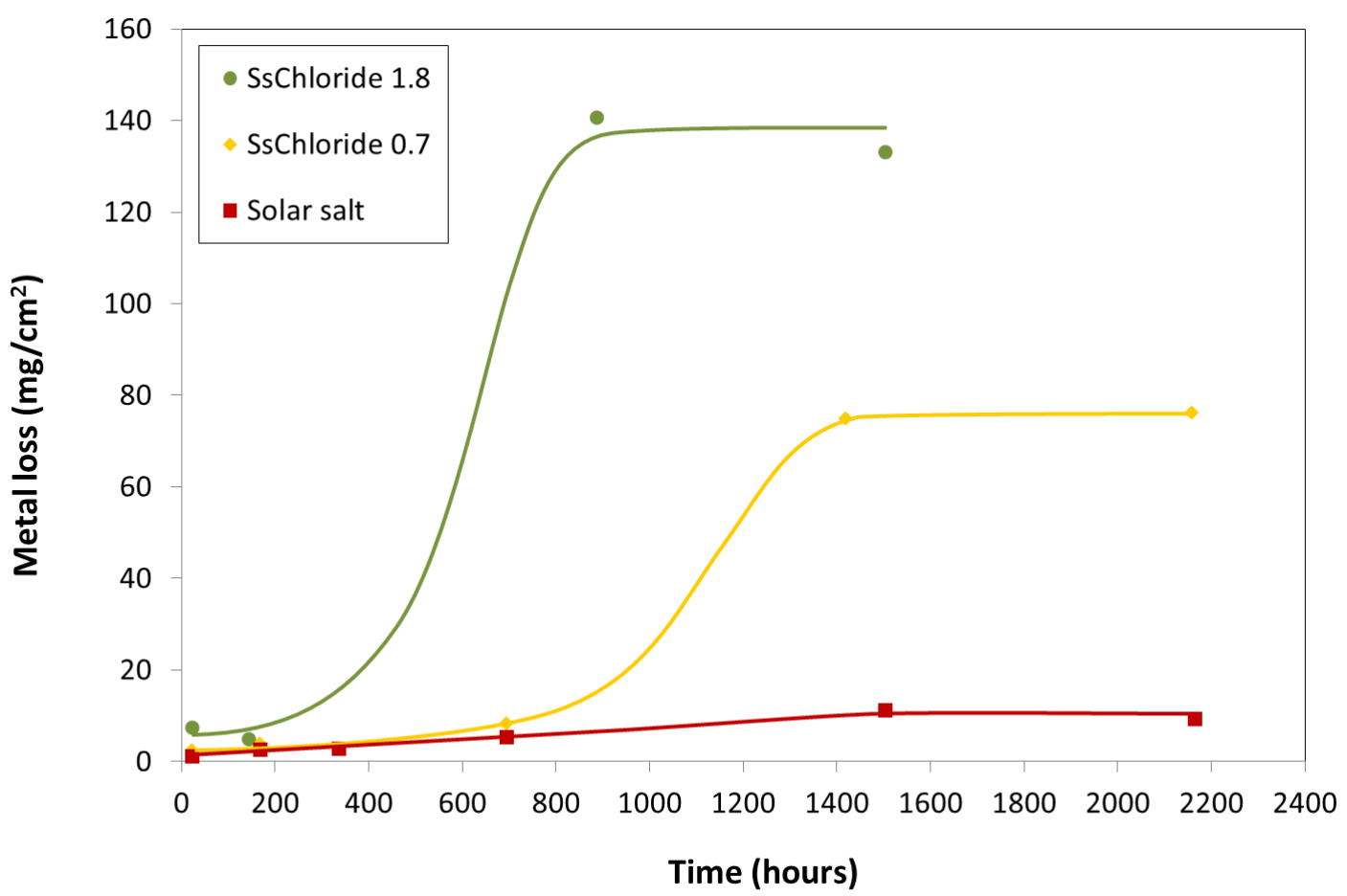

Figure 6. Steel loss per unit surface versus time of thermal treatment for different compositions of molten salts.

Samples exposed to Solar salt are nearly unaffected until at least thirty days passed. After this time, the corrosive process slightly increases resulting in a steel loss of nearly $10 \mathrm{mg} / \mathrm{cm}^{2}$, which seems to be maintained for longer exposure times. For those samples exposed to SsChloride 0.7 the behaviour is very similar, thus indicating that there is no great effect of low amounts of chloride on corrosion of steel up to half a month. After that, the steel loss increases significantly until reaching a maximum after 60 days, which is maintained 30 days later, thus indicating that a passivation layer is formed that prevents the formation of oxide. For the samples exposed to SsChloride1.8, the results are much more notable. Although no linear behaviour is observed, it is clear that a chloride threshold affects the kinetics, which not only seems to be faster when chloride content is higher, but also to get the specimens corroded earlier, agreeing with previous studies of corrosion tests at short-term. Maximum oxide layer thickness is reached at shorter times (30 days before) although the metal loss is nearly double compared to the lower chloride content, and nearly 10 times the amount lost when no chloride has been added to Solar salt. Some studies have been found about the effect of chloride on corrosion of carbon steel in molten salts, but all of them performed with lower chloride content (up to 1\%), and for shorter times (up to nearly 30 days). The general conclusion is that the corrosion increases when 
increasing the amount of chloride in the molten salts [19][20][21][22][23]. Although it is clear that nitrates produce corrosion in steels at high temperatures, it has also been demonstrated that a passivation process occurs since a protective layer formed mainly by $\mathrm{Fe}_{3} \mathrm{O}_{4}$ is formed. However, this protective layer not only can get the metal surface to be passivated at the beginning, but also produces deformation and vacancies in the microstructure, and the corrosive processes is aggravated at long exposure times. Chloride ions can be adsorbed on the oxide layer. Whether the $\mathrm{Cl}^{-}$concentration is low, the greatest part of the metal surface remains unaffected. Nevertheless, when the activity of chlorides overcomes the oxide layer, pitting mechanism occurs and chloride ions are incorporated to the metal base resulting in an increasing of the anodic dissolution of the metal [24]. Therefore, higher corrosion results are observed. In addition, the presence of chloride at the metal-scale interface confirms the corrosion mechanism, involving iron chloride that had a key role in the corrosion process [18].

\section{Conclusions}

DGA methodology has been demonstrated as a technique yielding to more accurate results than ASTM standard (G1-03) for determining the corrosion on a metal plate. By equating the first and second derivatives of the polynomic curve describing the experimental data to zero, the amount of oxide formed during thermal treatments can be obtained, avoiding technician handling. The kinetics processes observed through this study clearly show no linear tendency due to the complex mechanisms appeared when the thermal-corrosive treatment is proceed at $400{ }^{\circ} \mathrm{C}$ and under $\mathrm{N}_{2}$ atmosphere. Thus, corrosion is affected only by the time factor when molten salts contain low chloride percentages. Under this condition, only after 30 days of exposure time the steel loss increases, reaching a maximum 30 days later. For higher amounts of chloride the behaviour is similar, although the corrosion rate is faster and the thickness of the oxide layer is thicker.

These results highlighted that a threshold value of chloride content makes the corrosive kinetics to be highly increased when it is overtaken.

\section{Acknowledgements}

The research leading to these results has received funding from Spanish goverment (Cdti-Fondo tecnológico IDI-20090393, ConSOLida Cdti-CENIT 2008-1005). The work is partially funded by the Spanish government (ENE2011-22722). The research leading to these results has received funding from the European Union's Seventh Framework Programme (FP7/2007-2013) under grant agreement $n^{\circ}$ PIRSES-GA-2013-610692 (INNOSTORAGE) and from the European Union's Horizon 2020 research and innovation programme under grant agreement No 657466 
(INPATH-TES). The authors would like to thank the Catalan Government for the quality accreditation given to the research group DIOPMA (2014 SGR 1543). Dr. Camila Barreneche would like to thank Ministerio de Economía y Competitividad de España for her grant Juan de la Cierva FJCI-2014-22886.

\section{References}

[1] D. Arzivu, P. Balaya, L. Cabeza, T. Hollands, A. Jäger-Waldau, M. Kondo, C. Konseibo, V. Meleshko, W. Stein, Y. Tamaura, H. Xu, and R. Zilles, 'Direct Solar Energy', in IPCC Special Report: Renewable Energy Sources and Climate Change Mitigation, O. Edenhofer, R. Pichs-Madruga, Y. Sokona, K. Seyboth, P. Matschoss, S. Kadner, T. Zwickel, P. Eickemeier, G. Hansen, S. Schlomer, and C. von Stechow, Eds. Cambridge, United Kingdom and New York, NY, USA: Cambridge University Press, 2011, pp. 333400.

[2] P. Nejat, F. Jomehzadeh, M. M. Taheri, M. Gohari, and M. Z. Abd. Majid, 'A global review of energy consumption, $\mathrm{CO} 2$ emissions and policy in the residential sector (with an overview of the top ten CO2 emitting countries)', Renew. Sustain. Energy Rev., vol. 43, pp. 843-862, 2015.

[3] UNEP, Towards a Green Economy: Pathways to Sustainable Development and Poverty Eradication. 2011.

[4] C. Le Quéré, M. R. Raupach, J. G. Canadell, and G. M. Al., 'Trends in the sources and sinks of carbon dioxide', Nat. Geosci., vol. 2, no. 12, pp. 831 - 836, 2009.

[5] I. Dincer, 'Renewable energy and sustainable development: a crucial review', Renew. Sustain. Energy Rev., vol. 4, no. 2, pp. 157-175, 2000.

[6] I. Dincer and M. a Rosen, 'A worldwide perspective on energy, environment, and sustainable development', Int. J. Energy Res., vol. 22, no. 15, pp. 1305-1321, 1998.

[7] D. Ürge-Vorsatz, L. F. Cabeza, S. Serrano, C. Barreneche, and K. Petrichenko, 'Heating and cooling energy trends and drivers in buildings', Renew. Sustain. Energy Rev., vol. 41, pp. 85-98, 2015.

[8] A. Gil, M. Medrano, I. Martorell, A. Lazaro, P. Dolado, B. Zalba, and L. F. Cabeza, 'State of the art on high temperature thermal energy storage for power generation. Part 1Concepts, materials and modellization', Renew. Sustain. Energy Rev., vol. 14, no. 1, pp. $31-55,2010$.

[9] K. Vignarooban, X. Xu, a. Arvay, K. Hsu, and a. M. Kannan, 'Heat transfer fluids for 
concentrating solar power systems - A review', Appl. Energy, vol. 146, pp. 383-396, 2015.

[10] J. W. Raade and D. Padowitz, 'Development of Molten Salt Heat Transfer Fluid With Low Melting Point and High Thermal Stability', J. Sol. Energy Eng., vol. 133, no. 3, p. 031013, 2011.

[11] T. Bauer, N. Pfleger, D. Laing, M. Eck, and S. Kaesche, 'High-Temperature Molten Salts for Solar Power Application', in Molten Salts Chemistry, H. Lantelme, F.; Groult, Ed. Burlington, MA, USA: Elsevier Inc., 2013, pp. 415-438.

[12] A. Hoshi, D. R. Mills, A. Bittar, and T. S. Saitoh, 'Screening of high melting point phase change materials (PCM) in solar thermal concentrating technology based on CLFR', Sol. Energy, vol. 79, no. 3, pp. 332-339, 2005.

[13] C. E. Bradshaw, R.W.; Tyner, 'Chemical and Engineering Factors Affecting Solar Central Receiver Applications of Ternary Molten Salts - SAND88-8686', 1988.

[14] S. D. Cramer and B. S. Covino, Eds., 'Corrosion by Molten Nitrates, Nitrites, and Fluorides', in ASM Handbook Volume 13A, Corrosion: Fundamentals, Testing, and Protection, ASM International, 2003, pp. $124-128$.

[15] S. H. Bradshaw, R.W.; Goods, 'Corrosion of Alloys and Metals by Molten Nitrates', in High Temperature Corrosion in Molten Salts, C. A. C. Sequeira, Ed. Zurich, Switzerland: Trans Tech Publlications INC., 2003, pp. 117-134.

[16] ASTM, 'ASTM G1 Standard Practice for Preparing, Cleaning, and Evaluation Corrosion Test Specimens', 2003.

[17] T. Bauer, N. Pfleger, N. Breidenbach, M. Eck, D. Laing, and S. Kaesche, 'Material aspects of Solar Salt for sensible heat storage', Appl. Energy, vol. 111, pp. 1114-1119, 2013.

[18] A. Sole, L. Miro, C. Barreneche, I. Martorell, and L. F. Cabeza, 'Corrosion of metals and salt hydrates used for thermochemical energy storage', Renew. Energy, vol. 75, pp. 519$523,2015$.

[19] R. W. Bradshaw and W. M. Clift, 'Effect of Chloride Content of Molten Nitrate Salt on Corrosion of a516 Carbon Steel - SAND2010-7594', Albuquerque, NM and Livermore, CA, USA, 2010.

[20] R. Notoya, T.; Ishikawa, T.; Midorikawa, 'Corrosion Behavior of Iron and Low Carbon Steels in Molten Alkali Nitrates Containing Alkali Halide', in Proc. Fifth International Congress on Metallic Corrosion, 1972, p. 1039. 
[21] A. I. El Hosary, A.A.; Baraka, A.; Abdel-Rohman, 'Effects of Halides on the Corrosion of Mild Steel in Molten NaNO3-KNO3 Eutectic', Br. Corros. J., vol. 11, no. 4, pp. 228230, 1976.

[22] I. B. Singh and U. Sen, 'The effect of $\mathrm{NaCl}$ addition on the corrosion of mild steel in NaNO3 melt', Corros. Sci., vol. 34, no. 10, pp. 1733-1742, Oct. 1993.

[23] S. H. Goods, R. W. Bradshaw, M. R. Prairie, and J. M. Chavez, 'Corrosion of Stainless and Carbon Steels in Molten Mixtures of Industrial Nitrates - SAND94-8211', Albuquerque, NM and Livermore, CA, USA, 1994.

[24] M. B. Valcarce and M. Vazquez, 'Carbon steel passivity examined in alkaline solutions: The effect of chloride and nitrite ions', Electrochim. Acta, vol. 53, no. 15, pp. 5007$5015,2008$. 